\title{
Effect of Heat Treatment on the Phase Transformation and Magnetic Properties of the Rapidly Solidified $\mathrm{Pr}_{9} \mathrm{Fe}_{58} \mathrm{Co}_{13} \mathrm{Zr}_{1} \mathrm{Nb}_{4} \mathrm{~B}_{15}$ Alloy Ribbons
}

\author{
K. PAWLIK* \\ Institute of Physics, Częstochowa University of Technology, al. Armii Krajowej 19, 42-201 Częstochowa, Poland
}

\begin{abstract}
The rapidly solidified ribbon samples of the $\operatorname{Pr}_{9} \mathrm{Fe}_{58} \mathrm{Co}_{13} \mathrm{Zr}_{1} \mathrm{Nb}_{4} \mathrm{~B}_{15}$ alloy subjected to short time annealing at temperatures ranging from $923 \mathrm{~K}$ to $1033 \mathrm{~K}$ were investigated. The phase analysis supported by the Rietveld refinement was used to identify the phase constitution. The results of Rietveld calculations were confirmed by transimission electron microscopy and $M(T)$ studies. Measurement of recoil curves allowed the determination of switching field distributions and $\delta M$ plots for samples annealed at various temperatures.
\end{abstract}

DOI: 10.12693/APhysPolA.131.1264

PACS/topics: 75.20.En, 71.70.Gm, 75.50.Vv, 75.50.Ww

\section{Introduction}

Pr-Fe-B magnets of low Pr concentration seem to be an attractive alternative to more popular $\mathrm{Nd}-\mathrm{Fe}-\mathrm{B}$ counterparts due to a possibility of their applications at low temperatures. The argument for that is the fact that the hard magnetic $\mathrm{Nd}_{2} \mathrm{Fe}_{14} \mathrm{~B}$ phase undergoes a significant reduction of magnetocrystalline anisotropy below $150 \mathrm{~K}$ due to the spin reorientation in this phase [1]. Replacement of $\mathrm{Nd}$ by $\mathrm{Pr}$ in the alloy composition results in a decrease of the spin-reorientation temperature down to $25 \mathrm{~K} \mathrm{[2]} \mathrm{and} \mathrm{maintaining} \mathrm{good} \mathrm{performance} \mathrm{of} \mathrm{hard}$ magnetic devices above this temperature. Additionally, Betancourt and Davies [3] reported that addition of $\mathrm{Nb}$ and $\mathrm{Zr}$ led to the improvement of magnetic properties of nanocomposite $(\mathrm{Pr}, \mathrm{Nd}-\mathrm{Fe}-\mathrm{B})$ magnets by restraining the growth of metastable phases and increasing the content of the hard magnetic phase [4].

In our recent work [5], we have reported on rapidly solidified ribbons of $\operatorname{Pr}_{9} \mathrm{Fe}_{50+x} \mathrm{Co}_{13} \mathrm{Zr}_{1} \mathrm{Nb}_{4} \mathrm{~B}_{23-x}(x=0$, $2,5,8)$ alloys. It was shown that as-cast ribbons were fully amorphous and revealed soft magnetic properties. The differential scanning calorimetry (DSC) and differential thermal analysis (DTA) studies have revealed high values of the activation energy for crystallization $E_{a}$ for all alloy compositions that indicate good thermal stability of an amorphous phase. The $E_{a}$ reaches $498 \mathrm{~kJ} / \mathrm{m}^{3}$ for $x=2$ alloy and decreases with increasing $\mathrm{Fe}$ content down to $E_{a}=420 \mathrm{~kJ} / \mathrm{m}^{3}$ for $x=8$ alloy. Furthermore, the large supercooled liquid region before crystallization $\Delta T_{x}$ of $\approx 100 \mathrm{~K}$ for $x=2,5$ and 8 alloys is related to simultaneous crystallization of two phases. Short time annealing resulted in crystallization and thus changes of the magnetic properties. The ribbons annealed for $5 \mathrm{~min}$ at temperatures ranging from 923 to $1033 \mathrm{~K}$ exhibited high coercivities. Our studies have shown that magnetic properties depend both on the heat treatment temperature and the chemical composition of the alloy. The highest value of coercivity $(\approx 1100 \mathrm{kA} / \mathrm{m})$ was measured for $\mathrm{Pr}_{9} \mathrm{Fe}_{58} \mathrm{Co}_{13} \mathrm{Zr}_{1} \mathrm{Nb}_{4} \mathrm{~B}_{15}$ alloy ribbons. In the present work, detailed studies of evolution of the phase constitution and microstructure with the annealing temperature and the impact of these factors on the magnetic properties of the $\operatorname{Pr}_{9} \mathrm{Fe}_{58} \mathrm{Co}_{13} \mathrm{Zr}_{1} \mathrm{Nb}_{4} \mathrm{~B}_{15}$ rapidly solidified ribbons are presented.

\section{Samples preparation and experimental methods}

The ribbon samples of $\operatorname{Pr}_{9} \mathrm{Fe}_{58} \mathrm{Co}_{13} \mathrm{Zr}_{1} \mathrm{Nb}_{4} \mathrm{~B}_{15}$ alloy were produced by the controlled atmosphere single roll melt-spinning technique at the velocity of the copper roll surface of $25 \mathrm{~m} / \mathrm{s}$. Subsequently the samples were sealed off in a quartz tube under low pressure of argon and heat treated at temperatures ranging from $923 \mathrm{~K}$ to $1033 \mathrm{~K}$ for $5 \mathrm{~min}$. The phase constitution of devitrified ribbons was determined by the qualitative analysis of Xray diffraction (XRD) patterns supported by the Rietveld refinement. The XRD patterns were collected using the Bruker D8 Advance diffractometer with $\mathrm{Cu} K_{\alpha}$ radiation equipped with a LynxEye detector (linear focus of $25 \mathrm{~mm}$, primary beam divergence slit $-0.6 \mathrm{~mm}$ ) with Soller slits on a primary and diffracted beam. The measurements were performed in the Bragg-Brentano configuration with a $K_{\beta}$ filter on the detector side. The $2 \theta$ step size was $0.02 \mathrm{deg}$ and step time $5 \mathrm{~s}$. The Rietveld refinements were performed using DIFFRAC SUITE TOPAS 4.2 software [6] in $2 \theta$ range from $30 \mathrm{deg}$ to $90 \mathrm{deg}$. The profile shapes were modeled with the TCHZ function. Additionally the quantitative phase structure analysis was performed by the PONKCS method [7].

The microstructure was examined by transmission electron microscopy (TEM). To determine the Curie temperatures $T_{c}$ of constituent phases, the magnetization $J$ versus temperature $T$ measurements, using the Faraday magnetic balance, over the temperature range $300-850 \mathrm{~K}$ and at a heating rate of $10 \mathrm{~K} / \mathrm{min}$ were performed. Hysteresis loops were measured using LakeShore VSM 7307 operating in external magnetic fields up to $2 \mathrm{~T}$ at room 
temperature. In order to calculate the switching field distributions and $\delta M$ plots, the recoil curves were measured for the initially saturated and initially demagnetized specimens.

\section{Results and discussion}

The X-ray diffraction patterns measured for samples annealed at various temperatures with the phase identification are presented in Fig. 1. For the sample annealed at $923 \mathrm{~K}$, two crystalline phases were identified: the paramagnetic $\mathrm{Pr}_{1+x} \mathrm{Fe}_{4} \mathrm{~B}_{4}$ (1:4:4) and hard magnetic $\mathrm{Pr}_{2}(\mathrm{Fe}, \mathrm{Co}){ }_{14} \mathrm{~B}(2: 14: 1)$. However the peak positions of these phases are strongly overlapped. Although these two phases were identified for all annealing temperatures, the presence of the amorphous phase was not clear for temperatures higher than $923 \mathrm{~K}$. Annealing at $1013 \mathrm{~K}$ resulted in crystallization of the additional soft magnetic $\alpha$-Fe phase.

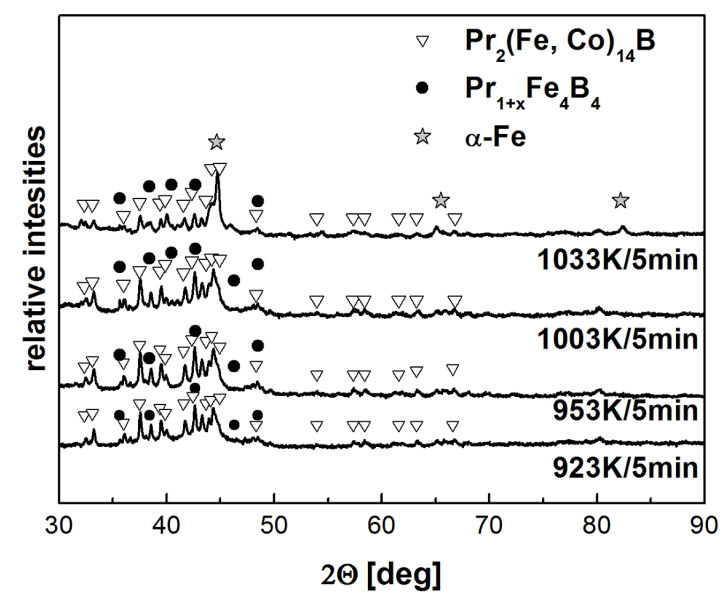

Fig. 1. The XRD patterns measured for $\mathrm{Pr}_{9} \mathrm{Fe}_{58} \mathrm{Co}_{13} \mathrm{Zr}_{1} \mathrm{Nb}_{4} \mathrm{~B}_{15}$ alloy ribbons annealed at various temperatures for $5 \mathrm{~min}$, with marked crystalline phases.

\section{TABLE I}

The criteria of fit: $R_{\exp }-R$-expected, $R_{w p}-$ $R$-weighted pattern and GOF - goodness of fit for the Rietveld refinement of XRD patterns of $\mathrm{Pr}_{9} \mathrm{Fe}_{58} \mathrm{Co}_{13} \mathrm{Zr}_{1} \mathrm{Nb}_{4} \mathrm{~B}_{15}$ alloy ribbons annealed at various temperatures.

\begin{tabular}{c|c|c|c}
\hline \hline & $R_{\exp }$ & $R_{w p}$ & $G O F$ \\
\hline $923 \mathrm{~K}$ & 0.493 & 0.727 & 1.472 \\
$953 \mathrm{~K}$ & 0.486 & 0.809 & 1.668 \\
$1003 \mathrm{~K}$ & 0.508 & 0.857 & 1.687 \\
$1033 \mathrm{~K}$ & 0.499 & 1.081 & 2.174
\end{tabular}

For detailed determination of the phase constitution, and in order to address the issue of amorphous phase presence in the annealed samples, the series of the Rietveld refinements were performed. The refined patterns with corresponding difference curves are presented

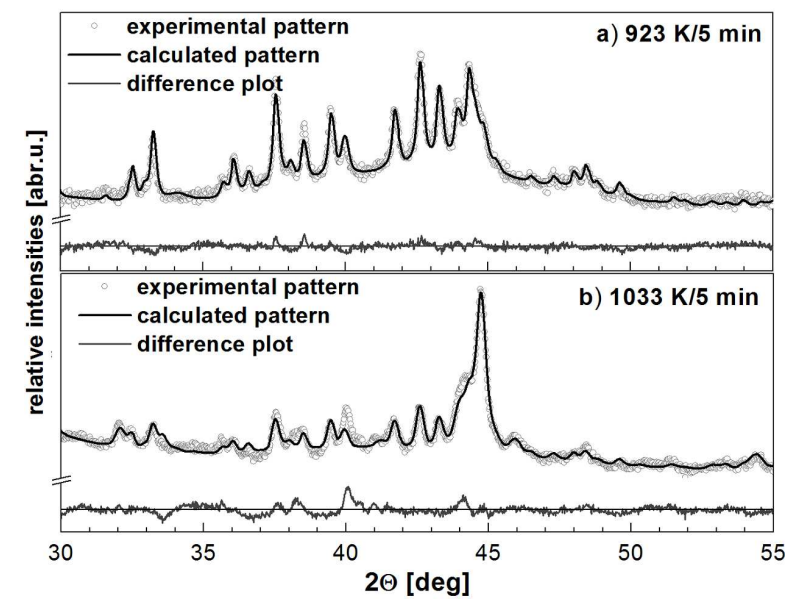

Fig. 2. The experimental and calculated diffraction patterns with corresponding difference curves for $\operatorname{Pr}_{9} \mathrm{Fe}_{58} \mathrm{Co}_{13} \mathrm{Zr}_{1} \mathrm{Nb}_{4} \mathrm{~B}_{15}$ alloy ribbons annealed at $923 \mathrm{~K}(\mathrm{a})$ and $1033 \mathrm{~K}(\mathrm{~b})$.

in Fig. 2. The criteria of fit $R$ are collected in Table I. In Table II the starting and final model parameters values are presented. In the starting model the presence of two crystalline phases 1:4:4 and 2:14:1 for all annealing temperatures were considered. Quantification of the amorphous phase is not possible in traditional Rietveld analysis [8]. One of commonly used methods to overcome this problem is the technique known as PONKCS [7] (Partial Or No Known Crystal Structure) that can be classified as an internal standard method. The PONKCS analysis is based on determining the $Z M V$ parameter for the amorphous phase. This parameter is easily derived when the structure of phase is well known $(Z M$ is the mass and $V$ the volume of the unit cell) [9]. Using these $Z M V$ values one can calculate the weight fractions of constituent phases. However, any phase that is not included in the model will not be considered in these calculations. Therefore if an amorphous or any unidentified crystalline phase has not been incorporated in the model, only the relative fractions of known phases can be calculated. The method will return the sum of analyzed phases as $100 \%$ regardless of the sample components not numbered in the starting model. For amorphous phase structural details are not available. However it is possible to represent the amorphous phase with a group of peaks (peaks phase). The value of $Z M V$ parameter for such a phase can be derived by measuring the diffraction pattern for the mixture of a known amount of the phase of interest with the well-characterized internal standard. Such a $Z M V$ value has no physical significance and serves as a calibration value for the later phase concentration calculations in samples under investigation. In the present work, the diffraction pattern was measured for defined mixture of as-cast amorphous ribbons with the standard $\alpha$-Fe. The amorphous phase was incorporated into the starting structural model by treating the amorphous bump as 
the "peaks-phase" signal consisting of three broad TCHZ peaks. From the refinement, the $Z M V$ parameter for the amorphous phase was determined. Subsequent calculations have shown that the amorphous component was present in the samples annealed up to $1003 \mathrm{~K}$. The amorphous phase content decreases with increasing annealing temperature. For the samples annealed at $1003 \mathrm{~K}$ and
$1033 \mathrm{~K}$ the $\alpha$-Fe phase had to be incorporated into the starting model to obtain the best fit. In the case of sample annealed at $1033 \mathrm{~K}$ the difference curve has shown that at least one additional crystalline phase had to be included to the model. Furthermore, detailed identification and subsequent Rietveld refinement have shown the presence of $\mathrm{Pr}_{2} \mathrm{O}_{3}$ phase in this sample.

TABLE II

Refined lattice parameters for crystalline phases identified for $\operatorname{Pr}_{9} \mathrm{Fe}_{58} \mathrm{Co}_{13} \mathrm{Zr}_{1} \mathrm{Nb}_{4} \mathrm{~B}_{15}$ alloy ribbons annealed at various temperatures.

\begin{tabular}{|c|c|c|c|c|c|c|}
\hline $\begin{array}{c}\text { Phase } \\
\text { space group }\end{array}$ & $\begin{array}{r}\mathrm{Pr}_{2}(\mathrm{Fe} \\
\quad P 4_{2}\end{array}$ & $\begin{array}{l}\mathrm{Co})_{14} \mathrm{~B} \\
m n m\end{array}$ & $\begin{array}{r}\mathrm{PrF} \\
P c \\
\end{array}$ & & $\begin{array}{c}\alpha-\mathrm{Fe} \\
I m-3 m\end{array}$ & $\begin{array}{c}\mathrm{Pr}_{2} \mathrm{O}_{3} \\
I a-3\end{array}$ \\
\hline parameter & $a[\mathrm{~nm}]$ & $c[\mathrm{~nm}]$ & $a[\mathrm{~nm}]$ & $c[\mathrm{~nm}]$ & $a[\mathrm{~nm}]$ & $a[\mathrm{~nm}]$ \\
\hline initial & 0.8811 & 1.2231 & 0.7117 & 3.50699 & 0.2868 & 1.1156 \\
\hline $923 \mathrm{~K}$ & $0.87617 \pm 0.00005$ & $1.21450 \pm 0.00009$ & $0.73657 \pm 0.00042$ & $3.55503 \pm 0.00625$ & - & - \\
\hline $953 \mathrm{~K}$ & $0.87671 \pm 0.00006$ & $1.21541 \pm 0.00010$ & $0.73807 \pm 0.00028$ & $3.54203 \pm 0.00294$ & - & - \\
\hline $1003 \mathrm{~K}$ & $0.87584 \pm 0.00006$ & $1.21389 \pm 0.00012$ & $0.73971 \pm 0.00014$ & $3.47838 \pm 0.00143$ & $0.2883 \pm 0.0008$ & - \\
\hline $1033 \mathrm{~K}$ & $0.87647 \pm 0.00008$ & $1.21557 \pm 0.00021$ & $0.67882 \pm 0.00039$ & $3.54994 \pm 0.00238$ & $0.2869 \pm 0.0003$ & $1.1195 \pm 0.0002$ \\
\hline
\end{tabular}

TABLE III

Crystallite sizes $\left(L_{v o l}\right)$ and weight fractions of constituent phases calculated by the Rietveld method for $\mathrm{Pr}_{9} \mathrm{Fe}_{58} \mathrm{Co}_{13} \mathrm{Zr}_{1} \mathrm{Nb}_{4} \mathrm{~B}_{15}$ alloy ribbons annealed at various temperatures.

\begin{tabular}{|c|c|c|c|c|c|c|c|c|c|}
\hline $\begin{array}{l}\text { Phase name } \\
\text { space group }\end{array}$ & \multicolumn{2}{|c|}{$\begin{array}{c}\mathrm{Pr}_{2}(\mathrm{Fe}, \mathrm{Co})_{14} \mathrm{~B} \\
\mathrm{P}_{4} / \mathrm{mnm}\end{array}$} & \multicolumn{2}{|c|}{$\begin{array}{c}\mathrm{PrFe}_{4} \mathrm{~B}_{4} \\
\text { Pccn }\end{array}$} & \multicolumn{2}{|c|}{$\begin{array}{c}\alpha-\mathrm{Fe} \\
I m-3 m\end{array}$} & \multicolumn{2}{|c|}{$\begin{array}{c}\mathrm{Pr}_{2} \mathrm{O}_{3} \\
I a-3\end{array}$} & $\begin{array}{c}\text { amorphous } \\
- \\
\end{array}$ \\
\hline parameter & $L_{v o l}[\mathrm{~nm}]$ & [wt\%] & $L_{v o l}[\mathrm{~nm}]$ & [wt\%] & $L_{\text {vol }}[\mathrm{nm}]$ & [wt\%] & $L_{\text {vol }}[\mathrm{nm}]$ & [wt\%] & [wt\%] \\
\hline $923 \mathrm{~K}$ & $41.2 \pm 1.4$ & $33.5 \pm 0.5$ & $7.2 \pm 0.3$ & $13.8 \pm 0.6$ & - & - & - & - & $52.8 \pm 0.4$ \\
\hline $953 \mathrm{~K}$ & $37.9 \pm 0.6$ & $49.3 \pm 0.4$ & $12.9 \pm 0.5$ & $10.9 \pm 0.4$ & - & - & - & - & $39.8 \pm 0.4$ \\
\hline $1003 \mathrm{~K}$ & $36.3 \pm 0.5$ & $65.1 \pm 0.6$ & $50.1 \pm 5.7$ & $8.5 \pm 0.6$ & $8.6 \pm 0.3$ & $11.8 \pm 0.2$ & - & - & $14.6 \pm 0.2$ \\
\hline $1033 \mathrm{~K}$ & $36.5 \pm 1.8$ & $56.1 \pm 1.4$ & $45.1 \pm 13.9$ & $5.5 \pm 0.6$ & $23.5 \pm 0.4$ & $32.0 \pm 1.1$ & $27.9 \pm 0.8$ & $6.4 \pm 0.3$ & - \\
\hline
\end{tabular}

Refined lattice parameters of 2:14:1 phase are smaller than starting values. This fact agrees well with the results obtained by Liu and Davies [10]. They established for $(\mathrm{Pr}, \mathrm{Nd})-(\mathrm{Fe}, \mathrm{Co})-\mathrm{B}$ alloys that the Co addition leads to a decrease of lattice parameters of $2: 14: 1$ phase.

Calculated crystallite sizes and the weight fractions of constituent phases are collected in Table III and temperature dependences of these parameters are presented in Fig. 3. The content of hard magnetic phase increases with annealing temperature reaching the highest value of $65 \mathrm{wt} \%$ for $1003 \mathrm{~K}$. This increase is accompanied by a significant decrease in the amount of the amorphous phase and a slight decrease of paramagnetic 1:4:4 phase content. The crystallite sizes (calculated as the volume weighted coherently diffracting domain sizes $\left.\left(L_{v o l}\right)\right)$ of a hard magnetic phase remain almost constant for all annealing temperatures while for the paramagnetic phase crystallites sizes increase with annealing temperature. Very fine crystallites of the $\alpha$-Fe phase $(\approx 8 \mathrm{~nm})$ appear at $1003 \mathrm{~K}$. Increasing the annealing temperature up to $1033 \mathrm{~K}$ led to significant enlargement of $\alpha$-Fe crystallite sizes and the increase of this phase content.

A relatively uniform microstructure consisting of grains of the average diameters of 30-60 $\mathrm{nm}$ for the sample annealed at $1003 \mathrm{~K}$ was revealed by TEM (Fig. 4a).
A corresponding electron diffraction pattern with distinguishable diffused ring confirms the presence of amorphous phase. Additionally, smaller nanocrystals of $\approx$ $10 \mathrm{~nm}$ diameters are marked in Fig. 4b. Measured grain sizes are in good agreement with the results of the Rietveld analysis.

The dependences of reduced magnetization on the temperature for all samples are presented in Fig. 5. For the lowest annealing temperature, two stages of dependence were measured confirming the presence of the amorphous phase. For higher annealing temperatures no such inflection was observed. Although, according to the Rietveld analysis the amorphous phase still exists in the samples. This is probably due to the increase of the weight fraction of the hard magnetic phase and reduction of the amorphous phase content. For annealing temperatures $1003 \mathrm{~K}$ and $1033 \mathrm{~K}$ the magnetization keeps relatively high values above the Curie temperature of the hard magnetic phase which confirms presence of the $\alpha$-Fe phase.

The Curie temperature was determined as the minimum of the temperature first derivative of magnetization. Its value reaches $665 \mathrm{~K}$ for sample annealed at $623 \mathrm{~K}$ and is higher than for pure $\operatorname{Pr}_{2} \mathrm{Fe}_{14} \mathrm{~B}\left(T_{c}=558 \mathrm{~K}\right)$. It was established for nanocrystalline $\mathrm{Pr}_{10} \mathrm{Fe}_{84} \mathrm{~B}_{6}$ ribbons that the Curie temperature of $\operatorname{Pr}_{2} \mathrm{Fe}_{14} \mathrm{~B}$ phase increases by 


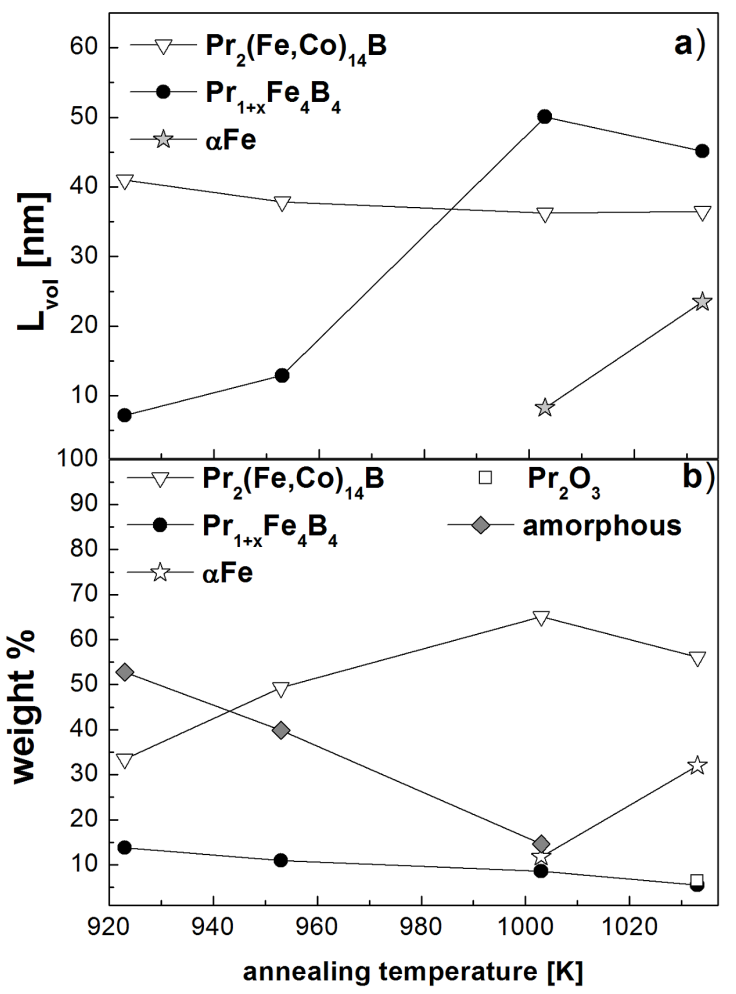

Fig. 3. Crystallite sizes $\left(L_{v o l}\right)$ (a) and weight fractions of constituent phases (b) dependences on annealing temperature for $\mathrm{Pr}_{9} \mathrm{Fe}_{58} \mathrm{Co}_{13} \mathrm{Zr}_{1} \mathrm{Nb}_{4} \mathrm{~B}_{15}$ ribbons.

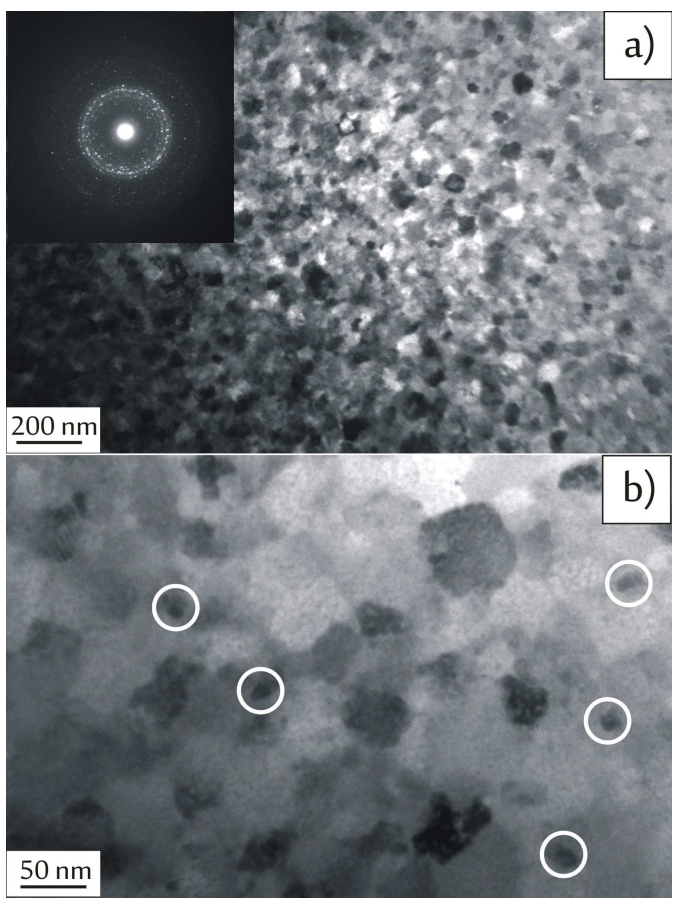

Fig. 4. Microstructure of ribbon annealed at $1003 \mathrm{~K}$ together with the electron diffraction pattern from the entire visible area (a) and the area with marked very fine grains (b).

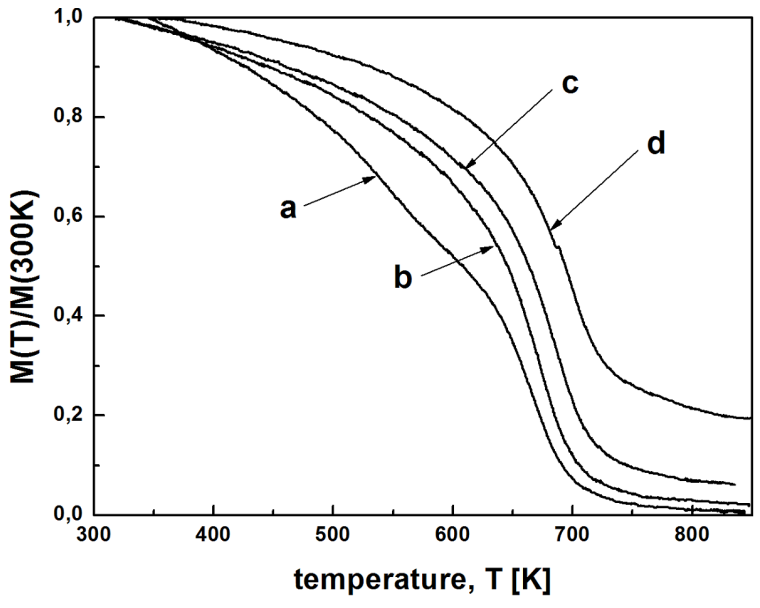

Fig. 5. The normalized magnetization versus temperature curves measured for the $\operatorname{Pr}_{9} \mathrm{Fe}_{58} \mathrm{Co}_{13} \mathrm{Zr}_{1} \mathrm{Nb}_{4} \mathrm{~B}_{15}$ alloy ribbon samples annealed at $923(a), 953(b), 1003(c)$, and $1033 \mathrm{~K}(d)$.

$\approx 9 \mathrm{~K}$ with each $1 \%$ of Co for Fe substitution [11] which is in good agreement with this result.

The hysteresis loops measured for ribbons annealed at various temperatures (a) and magnetic parameters dependences on annealing temperature (b) are presented in Fig. 6. The squareness of hysteresis loop (SQR) defined by the ratio of the reverse field required to reduce $J$ by $10 \%$ from the remanence to ${ }_{J} H_{c}$, were calculated for the measured demagnetization curves. The SQR values are $0.26,0.35,0.25$, and 0.06 for the samples annealed at 923, 953, 1003, and $1033 \mathrm{~K}$, respectively. Although the demagnetization curves have very favorable shapes for the annealing temperature up to $1003 \mathrm{~K}$, the SQR are rather low due to the step around the zero field shown in the inset of Fig. 6a.

Furthermore, a pronounced increase of coercivity ${ }_{J} H_{c}$ with the annealing temperature is observed. The ${ }_{J} H_{c}$ reaches the maximum value of $1089 \mathrm{kA} / \mathrm{m}$ for the sample annealed at $1003 \mathrm{~K}$. This is accompanied by a slight increase in saturation polarization with the annealing temperature from $J_{r}=0.79 \mathrm{~T}$ for $923 \mathrm{~K}$ to $J_{r}=0.91 \mathrm{~T}$ for $1033 \mathrm{~K}$. After heat treatment at $1033 \mathrm{~K}$, the coercivity drops to $541 \mathrm{kA} / \mathrm{m}$ and the shape of demagnetization curve changes causing significant decrease of $(\boldsymbol{B H})_{\max }$.

The series of recoil curves were measured for initially saturated $(D)$ and demagnetized $(R)$ samples and the irreversible remanence dependences on the reverse field $M_{i r r}^{D}(H)$ and $M_{i r r}^{R}(H)$ were constructed. Subsequently the first derivatives of $M_{i r r}(H)$ with respect to the applied magnetic field $\left(\mathrm{d} M_{i r r} / \mathrm{d} H\right)$ gave the switching field distributions (SFD) presented in Fig. 7. These dependences reflect the rate of irreversible remanence changes with the increase of maximum applied recoil field [12]. The profile of SFD peak can indirectly provide information about the homogeneity of the microstructure of the samples. The SFD peaks for samples annealed at $953 \mathrm{~K}$ 

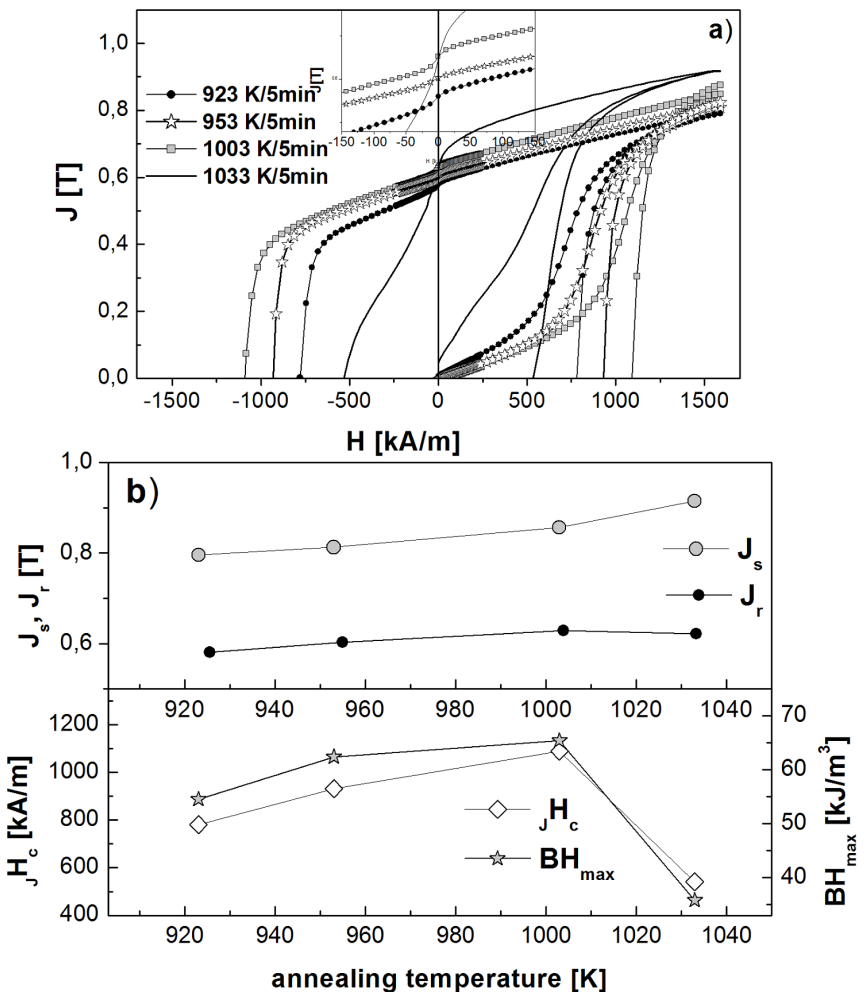

Fig. 6. The hysteresis loops measured for $\mathrm{Pr}_{9} \mathrm{Fe}_{58} \mathrm{Co}_{13} \mathrm{Zr}_{1} \mathrm{Nb}_{4} \mathrm{~B}_{15}$ alloy ribbons annealed at various temperatures (a) and magnetic parameters (saturation polarization $J_{s}$, remanence $J_{r}$, coercivity ${ }_{J} H_{c}$ and maximum energy product $\left.(\boldsymbol{B} \boldsymbol{H})_{\max }\right)$ dependences on annealing temperature (b).

and $1003 \mathrm{~K}$ are narrow and sharp with the maxima at 950 and $1100 \mathrm{kA} / \mathrm{m}$. These values are close to ${ }_{J} H_{c}$ of the samples. Such shapes indicate that the magnetization reversal occurs in a narrow field range and that the grains of the hard magnetic phase have uniform sizes. For the samples annealed at $1033 \mathrm{~K}$ the peak becomes slightly wider with the maximum shifted to lower fields $(\approx 800 \mathrm{kA} / \mathrm{m})$.

In order to determine at which points of hysteresis loops the interactions between grains enhance or reduce magnetization of the samples, the $\delta M(H)$ dependence can be calculated based on the modified StonerWohlfarth relation (Eq. (1)) [13]:

$$
\delta M(H)=I_{D}(H) / I_{R}(\infty)+2 I_{R}(H) / I_{R}(\infty)-1 .
$$

For the sample annealed at $1003 \mathrm{~K}, \delta M$ values increase to a sharp peak and decrease rapidly around the coercivity (Fig. 8). These positive $\delta M$ values indicate the existence of strong exchange coupling between grains. This is due to the high weight fraction of hard magnetic phase (65 wt\%) and the presence of soft magnetic phases: the amorphous and the nanocrystalline $\alpha$-Fe of very fine crystallite sizes. After the annealing at $1033 \mathrm{~K}$, the increase of weight fraction of $\alpha$-Fe phase at the expense of amorphous phase accompanied by the growth of grain sizes of

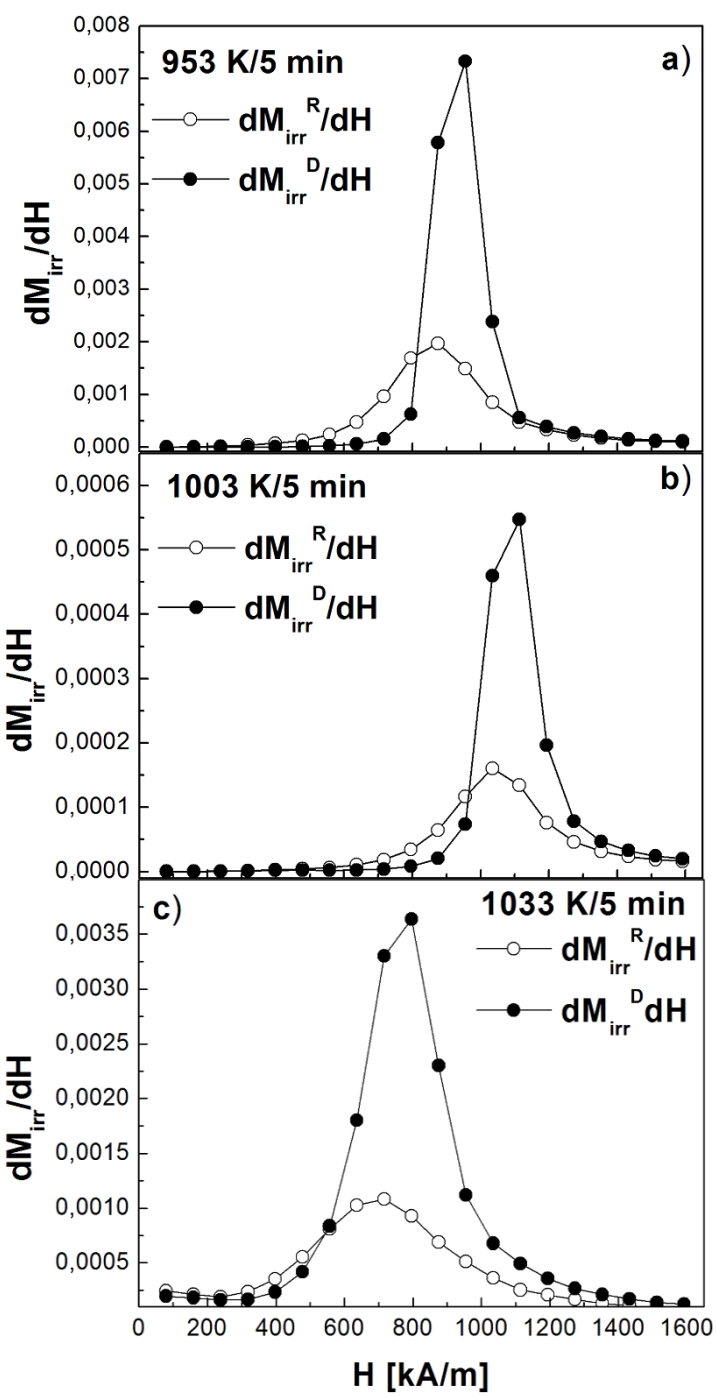

Fig. 7. The switching field distributions calculated for the $\mathrm{Pr}_{9} \mathrm{Fe}_{58} \mathrm{Co}_{13} \mathrm{Zr}_{1} \mathrm{Nb}_{4} \mathrm{~B}_{15}$ alloy ribbons annealed at various temperatures.

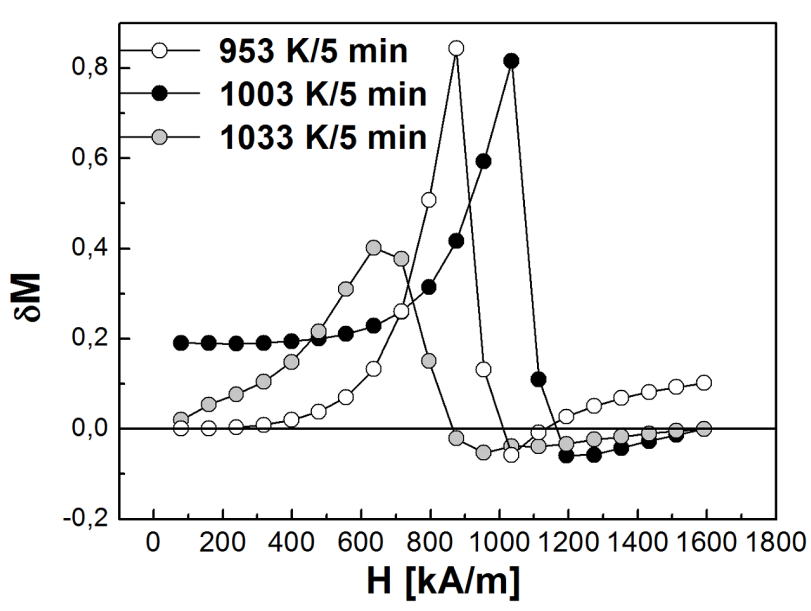

Fig. 8. The $\delta M$ plots for the $\operatorname{Pr}_{9} \mathrm{Fe}_{58} \mathrm{Co}_{13} \mathrm{Zr}_{1} \mathrm{Nb}_{4} \mathrm{~B}_{15}$ alloy ribbons annealed at various temperatures. 
$\alpha$-Fe led to a decrease of the level of exchange interactions. This has an effect in considerable reduction of the coercivity of the sample and changes of the demagnetization curve. The $\delta M$ peak becomes wider and its maximum shifts towards lower fields. Above $800 \mathrm{kA} / \mathrm{m}$ the dipolar interactions between grains become dominant.

\section{Conclusions}

Detailed studies of the phase constitution of $\mathrm{Pr}_{9} \mathrm{Fe}_{58} \mathrm{Co}_{13} \mathrm{Zr}_{1} \mathrm{Nb}_{4} \mathrm{~B}_{15}$ ribbon samples subjected to short time annealing have shown changes in the volume fractions of constituent phases with the annealing temperature. The Rietveld refinement of XRD scans using the PONKCS method made it possible to reveal presence of amorphous phase in samples annealed at temperatures up to $1003 \mathrm{~K}$. This method allowed us to determine the weight fractions of constituent phases and their crystallite sizes. The largest content of hard magnetic phase of mean crystallite diameters of $\approx 36 \mathrm{~nm}$ and small amount of very fine crystallites $(\approx 8 \mathrm{~nm})$ of soft magnetic $\alpha$-Fe was detected for the sample annealed at $1003 \mathrm{~K}$. This is accompanied by the best hard magnetic properties of this ribbon. Positive values of $\delta M$ parameter indicate the existence of strong exchange coupling between grains in this sample. Lower values of ${ }_{J} H_{c}$ and $(\boldsymbol{B} \boldsymbol{H})_{\max }$ for ribbons annealed below $1003 \mathrm{~K}$ have the origin in large fraction of the amorphous phase. The worsening of magnetic properties of samples annealed at $1033 \mathrm{~K}$ is related to the formation of large grains of $\alpha$-Fe and to the presence of $\mathrm{Pr}_{2} \mathrm{O}_{3}$ phase.

\section{References}

[1] Xue-Fu Zhong, W.Y. Ching, W. Lai, J. Appl. Phys. 70, 6146 (1991).

[2] Z. Liu, H.A. Davies, IEEE Trans. Magn. 40, 2898 (2004).

[3] I. Betancourt, H.A. Davies, J. Magn. Magn. Mater. 261, 328 (2003).

[4] C. Wang, M. Yan, W.Y. Zhang, Mater. Sci. Eng. B 123, 80 (2005).

[5] K. Pawlik, P. Pawlik, W. Kaszuwara, J.J. Wysłocki, Acta Phys. Pol. A 131, 979 (2017).

[6] Bruker AXS (2008): TOPAS V4: General profile and structure analysis software for powder diffraction data, User's Manual, Bruker AXS, Karlsruhe.

[7] N.V.Y. Scarlett, I.C. Madsen, Powder Diffr. 21, 278 (2006).

[8] H.M. Rietveld, J. Appl. Crystallogr. 2, 65 (1969).

[9] R.J. Hill, C.J. Howard, J. Appl. Crystallogr. 20, 467 (1987).

[10] Z.W. Liu, H.A. Davies, J. Phys. D Appl. Phys. 39, 2647 (2006)

[11] C.L. Harland, H.A. Davies, J. Appl. Phys. 87, 6116 (2000).

[12] P.I. Mayo, R.M. Erkilla, A. Bradbury, R.W. Chantrell, IEEE Trans. Magn. 26, 1894 (1990).

[13] P.E. Kelly, K. O'Grady, P.I. Mayo, R.W. Chantrell, IEEE Trans. Magn. 25, 3881 (1989). 